\title{
ESPANHOL COMO LÍNGUA ESTRANGEIRA (E/LE), ACCIÓN POÉTICA E XENOFOBIA: UMA EXPERIÊNCIA PEDAGÓGICA COM UM RECURSO EDUCACIONAL ABERTO NA PERSPECTIVA DOS LETRAMENTOS CRÍTICOS
}

\section{SPANISH AS A FOREIGN LANGUAGE (E/LE), POÉTIC ACTION AND XENOPHOBIA: A PEDAGOGICAL EXPERIENCE WITH AN OPEN EDUCATIONAL RESOURCE IN THE PERSPECTIVE OF CRITICAL LITERACY}

\section{André Firpo Beviláqua* Vilson José Leffa** Helena dos Santos Kieling ${ }^{* *}$}

\section{RESUMO}

O presente trabalho versa sobre a produção de Recursos Educacionais Abertos (REA) na perspectiva dos Letramentos Críticos. O objetivo geral do estudo é investigar em que medida um Recurso Educacional Aberto (REA) na perspectiva dos Letramentos Críticos pode propiciar (ou não) affordances para a produção de eventos discursivos sensíveis a problemas sociais como a xenofobia. Os objetivos específicos da pesquisa são três, a saber: a) Apresentar o REA desenvolvido (objetivos do material, princípios teórico-metodológicos que nortearam o seu desenvolvimento, materiais e ferramentas utilizados durante a sua produção, etc.); b) Analisar duas amostras dos eventos discursivos oriundos desse REA, com vistas a identificar indícios de Letramentos Críticos; c) Discutir possibilidades teórico-metodológicas para o redesign desse material. O estudo foi desenvolvido na disciplina "Oficina de Produção Textual", da Licenciatura em Letras Espanhol a Distância da Universidade Federal de Santa Maria, em parceria com a Universidade Aberta do Brasil (UFSM/UAB). Nesse sentido, apresenta características de uma pesquisa qualitativa de cunho fenomenológico (BOGDAN e BIKLEN, 1996). Os resultados da pesquisa indicam que REA na perspectiva dos Letramentos Críticos podem propiciar affordances para a produção de eventos discursivos sensíveis a problemas sociais como a xenofobia, uma vez que, apesar da pequena quantidade de amostras analisadas, foi possível identificar indícios de um Letramento Crítico no que diz

* Universidade Federal de Pelotas (UFPel), Pelotas, RS), Brasil. andre.firpo@gmail.com, https:// orcid. org/0000-0002-3169-3474

** Universidade Federal de Pelotas (UFPel), Pelotas,RS), Brasil.leffav@gmail.com, https://orcid. org/0000-0002-1605-5626

****Universidade Federal de Pelotas (UFPel), Pelotas, RS), Brasil. kieling.helena@gmail.com, https:// orcid.org/0000-0001-8899-8247 
respeito a tal questão. Esperamos, futuramente, ampliar o número de amostras, apontando também casos que tiveram menor sucesso, bem como motivações possíveis para isso.

Palavras-chave: Letramentos Críticos; REA; Xenofobia.

\section{ABSTRACT}

The present study is about the production of Open Educational Resources (OER) in the perspective of Critical Literacy. The overall objective of the study is to investigate to what extent an Open Educational Resource (OER) from the perspective of Critical Literacy can provide (or not) affordances for the production of discursive events sensitive to social problems such as xenophobia. The specific objectives of the research are three, namely: a) Present the developed OER (materials objectives, theoretical and methodological principles that guided its development, materials and tools used during its production, etc.); b) Analyze two samples of the discursive events from this OER, in order to identify indications of Critical Literacy; c) Discuss theoretical and methodological possibilities for the redesign of this material. The study was developed in the course "Textual Production Workshop", in the online bachelor's degree in Spanish at the Federal University of Santa Maria, in partnership with the Open University of Brazil (FUSM/OUB). In this sense, it presents characteristics of a qualitative research of a phenomenological nature (BOGDAN and BIKLEN, 1996). The results indicate that OER in the perspective of Critical Literacy can provide affordances for the production of socially sensitive discursive events such as xenophobia, since, despite the small sample analyzed, it was possible to identify traces of Critical Literacy. We hope, in the future, to increase the number of samples, also pointing out cases that had less success, as well as possible motivations for this.

Keywords: Critical Writing; OER; Xenophobia.

\section{CONSIDERAÇÕES INICIAIS}

Em agosto de 2017, inúmeros vídeos do ataque xenofóbico contra o refugiado sírio Mohamed Ali viralizaram nas redes sociais. Enquanto comercializava esfirras e outros alimentos da culinária árabe em uma movimentada esquina de Copacabana, Zona Sul do Rio de Janeiro, Mohamed foi surpreendido pela abordagem truculenta de outros ambulantes que atuavam no local. Munidos com pedaços de madeira, os trabalhadores brasileiros, além de derrubarem as mercadorias de Mohamed no chão, dirigiram diversas agressões verbais contra ele, tais como "Essa terra aqui é nossa! Vai tomar nosso lugar, não! Vai roubar nosso lugar, não!", "Vamos expulsar eles daqui!", "Vai, meu irmão, volta para o teu lugar, cara!", "Sai do meu país! Eu sou brasileiro!", "Nosso país está sendo invadido por estes homens-bomba miseráveis, 'esquartejados', que mataram crianças, adolescentes! Justiça! São miseráveis!" (ATAQUE, 2017).

$\mathrm{O}$ ataque contra Mohamed está longe de ser um caso isolado ou restrito ao âmbito nacional. No contexto brasileiro, contudo, manifestações desse tipo têm aumentado consideravelmente nos últimos anos, em sincronia com a forte 
onda de conservadorismo que se instaura no país. Outros casos que chamaram a atenção foram os ataques contra os médicos cubanos do Programa Mais Médicos, em 2013, na região Nordeste do Brasil (TALENTO, 2013), e contra os imigrantes venezuelanos, em 2018, na região Norte do país (MENDONÇA, 2018), entre outros.

Do ponto de vista de quem não concebe a neutralidade da educação (FREIRE, 2016), é imperioso que tensões sociais dessa natureza sejam tratadas em sala de aula, uma vez que costumam estar presentes, também, nas instâncias formais de ensino. Além disso, a xenofobia anda de mãos dadas com outros problemas sociais amplamente presentes no âmbito pedagógico, tais como o racismo, a discriminação de classe e outras formas de preconceito.

No tocante à educação linguística e ao ensino de línguas estrangeiras, um dos grandes desafios é o desenvolvimento de práticas pedagógicas que problematizem o papel de linguagens e suas tecnologias quanto à transformação do status quo de tais questões. Essa dificuldade tem sido encarada com seriedade pelo campo investigativo da Linguística Aplicada Crítica (LAC) e pela perspectiva transdisciplinar dos Letramentos Críticos, sobre os quais trataremos com mais profundidade na seção a seguir.

Tendo em vista as considerações precedentes, o presente trabalho tem como objetivo geral investigar em que medida um Recurso Educacional Aberto (REA) na perspectiva dos Letramentos Críticos pode propiciar (ou não) affordances para a produção de eventos discursivos sensíveis a problemas sociais como a xenofobia. Os objetivos específicos do estudo são três, a saber: a) Apresentar o REA desenvolvido (objetivos do material, princípios teórico-metodológicos que nortearam o seu desenvolvimento, materiais e ferramentas utilizados durante a sua produção, etc.); b) Analisar duas amostras dos eventos discursivos oriundos desse REA, com vistas a identificar indícios de Letramentos Críticos; c) Discutir possibilidades teóricometodológicas para o redesign desse material.

\section{LINGUÍSTICA APLICADA CRÍTICA, LETRAMENTOS CRÍTICOS E RECURSOS EDUCACIONAIS ABERTOS}

De acordo com Moita Lopes (2006), a Linguística Aplicada (LA) surgiu com o desafio principal de aplicar teorias linguísticas ao ensino de Línguas Estrangeiras (LE), com ênfase no ensino de língua inglesa. Conforme o autor, no entanto, com o amadurecimento do campo chegou-se ao entendimento de que o ensino de uma LE suscita uma série de questões psicológicas, sociais, etc. que fogem do escopo 
da disciplina de referência - a saber, a Linguística -, passando-se a argumentar, progressivamente, a favor de um arcabouço teórico interdisciplinar.

A Linguística Aplicada Crítica (LAC), por sua vez, suscita uma série de questões e interesses que, até então, não estavam nos desígnios da LA, tais como identidade, acesso, desigualdade, gênero, etc. (PENYCOOK, 2006). Para Penycook (2006), a preocupação da LAC vai além da construção de um campo investigativo transdisciplinar, mas de uma forma de antidisciplina ou conhecimento transgressivo, em que se faz necessário "(...) transgredir, política e teoricamente, os limites do pensamento e da ação tradicionais, não somente entrando em território proibido, mas tentando pensar o que não deveria ser pensado, fazer o que não deveria ser feito" (PENNYCOOK, 2006, p. 82).

Entre as possibilidades teórico-metodológicas para um trabalho nessa direção, encontra-se a perspectiva dos Letramentos Críticos, sumariamente entendida como um enfoque transdisciplinar que busca compreender o papel de linguagens e suas tecnologias na construção de uma sociedade mais responsiva a setores socialmente marginalizados, sobretudo no que diz respeito às questões de gênero, raça, classe, etc.

De acordo com Soares (2004), o conceito de Letramento surgiu em meados dos anos 1980, em sociedades tanto geograficamente quanto socioeconomicamente muito distantes, para fazer referência a "práticas sociais de leitura e de escrita mais avançadas e complexas que as práticas do ler e do escrever resultantes da aprendizagem do sistema de escrita" (SOARES, 2004, p. 6).

Paulo Freire não propôs, de forma explícita, a noção de Letramentos Críticos. No entanto, ninguém negaria que há, na obra do autor, um forte apelo nessa direção. É por isso que esse pedagogo crítico brasileiro costuma ser referenciado como um dos precursores dos Letramentos Críticos. Essa é também a visão de Cassany e Castellà (2010), conforme demonstra a citação a seguir:

Dito conceito foi aplicado ao campo do letramento nos anos sessenta pelo famoso pedagogo brasileiro Paulo Freire, que formulou com clareza a ideia de que os analfabetos são vítimas e não responsáveis de sua condição, que a escola é uma instituição criada por determinados grupos sociais para reproduzir o status quo (a pedagogia da opressão) e que o acesso ao letramento pode ser uma ferramenta importante de liberação ou empoderamento dos indivíduos. Ao aprender a ler, os sujeitos obtém poder ("empoderam-se") e podem transformar a realidade injusta que os rodeia (CASSANY E CASTELLÀ, 2010, p. 358, tradução nossa, grifos dos autores).

Para Cassany e Castellà (2010), com os quais temos concordado até o momento, além da Pedagogia Crítica, podemos rastrear, nas raízes dos Letramentos Críticos, campos investigativos como a Teoria Crítica, os Estudos Culturais e Políticos, os Estudos Linguísticos e Literários, o Pós-estruturalismo, os Novos 
Estudos do Letramento e a Análise Crítica do Discurso. Não pretendemos, neste estudo, aprofundar de que forma cada uma dessas áreas contribuiu para o desenvolvimento da noção de Letramentos Críticos, uma vez que outras publicações sobre o assunto já avançaram nessa direção (e.g. CASSANY E CASTELLÀ, 2010).

Caberia adicionar, ainda, uma breve consideração sobre a noção de crítica no âmbito dos estudos do Letramento. De acordo com Cassany e Castellà (2010), existem, pelo menos, três grandes orientações quanto a essa questão, a saber: a) Perspectiva tradicional ou filológica: o significado está no texto, e o código da escrita é a principal via de acesso para uma interpretação canônica ou erudita deste; b) Perspectiva interpretativa ou psicológica: o significado é um processo individual, mental, cognitivo, de conexão e de reelaboração, a partir dos conhecimentos prévios do leitor e das inferências necessárias para a interpretação do texto; c) Perspectiva crítica (subdividida em sociocultural e sociopolítica): o significado se constrói a partir da relação entre o texto e o contexto social, cultural e político em que este é interpretado pelo leitor. A diferença fundamental entre a perspectiva sociocultural e a sociopolítica é que, enquanto aquela aceita com mais facilidade o relativismo de interpretações, esta aponta para a necessidade de se "(...) questionar o sistema e atuar para transformá-lo (...)", ou seja, de "(...) mudar o mundo e lutar contra a injustiça e as desigualdades" (CASSANY e CASTELLÀ, 2010, p. 362-363, tradução nossa).

Ainda que, assim como Cassany e Castellà (2010), entendamos que manter uma fronteira rígida entre essas três orientações é tão difícil quanto desnecessário, a nossa principal preocupação provavelmente está na Perspectiva Crítica, com ênfase na dimensão sociopolítica. Essa orientação ao Letramento talvez seja a que mais se aproxima da ideia de crítica da Escola de Frankfurt, com a qual a noção de Letramentos Críticos está fortemente em dívida, conforme revela a citação a seguir:

(...) o esforço intelectual, e em última análise prático, por não aceitar sem reflexão e por simples hábito as ideias, os modos de atuar e as relações sociais dominantes; o esforço por harmonizar, entre si e com as ideias e metas da época, os setores afastados da vida social ${ }_{i}$ por deduzi-los geneticamente; por separar um do outro o fenômeno e a essência; por investigar os fundamentos das coisas, em uma palavra: por conhecê-las de maneira efetivamente real (HORKHEIMER, 2003, p. 287-288).

Além dos aspectos apresentados anteriormente, temos encontrado, no marco analítico tridimensional proposto por Fairclough (2008), importantes contribuições para a construção de um enfoque transdisciplinar dos Letramentos Críticos. De acordo com essa proposta, cada evento discursivo deve ser analisado de três formas complementares, conforme apresentamos, resumidamente, a seguir: a) texto: 
análise dos significados ideacionais (a representação do mundo e da experiência), interpessoais (a constituição das identidades pessoais e sociais, as relações entre as pessoas e as informações dadas versus as novas) e textuais (as formas-e-significados do texto, incluindo desde a forma mais genérica do texto até aspectos como a organização dialógica deste (turnos de fala, por exemplo), as relações coesivas entre as frases e entre as orações em frases complexas, a gramática da oração (a exemplo das questões de transitividade, modo e modalidade), etc. (HALLIDAY, 1978; 1985, apud FAIRCLOUGH, 2008); b) prática discursiva: a produção, distribuição e consumo do texto, incluindo as relações entre o evento discursivo e a ordem do discurso, bem como a constituição do evento discursivo a partir de diferentes gêneros e discursos; c) prática social: análise do contexto de situação (registro, por exemplo), do contexto institucional (por exemplo, esfera da atividade humana e gêneros do discurso) e do contexto mais amplo ou "de cultura" (aspectos sócio-políticos, culturais, etc.). De acordo com Fairclough (2008), questões como ideologia e poder podem estar presentes nesses três níveis.

Outra proposição que tem contribuído de forma consistente para o desenvolvimento de um enfoque transdisciplinar dos Letramentos Críticos são as etapas de Duboc (2015). Segundo a autora, essas etapas não devem ser entendidas de forma dogmática ou estanque, como uma espécie de cartilha a ser seguida pelo(a) educador(a), mas reinterpretada de acordo com as demandas de cada contexto, conforme vemos:

- Experiências com o conbecido: atividades que se voltam para experiências, saberes, interesses e perspectivas dos alunos (a partir do que lhes é familiar).

- Experiências com o novo: atividades que colocam o aluno em contato com novas experiências e perspectivas, convidando-o a conhecer o que não lhe é familiar ou a pensar sob uma perspectiva nova (momento de perturbar),

- Conceituações: momento em que o professor explica, argumenta ou descreve os objetivos da atividade, esclarecendo ao aluno o porquê daquela expansão para além do livro didático, por exemplo;

- Conexões locais e globais: consciência da multiplicidade de sentidos em diferentes escalas (locais e globais), ou seja, "se eu falo de uma escala local, o sentido será $\mathrm{X}_{\text {; }}$ se eu falo de uma escala global, o sentido poderá ser $\mathrm{Y}^{\prime \prime}$.

- Expansão de perspectiva: ampliação da visão de mundo do aluno por meio da consciência e do reconhecimento da heterogeneidade e multiplicidade de sentidos e sua influência sobre a constituição da linguagem, identidade e valores (MONTE MÓR, 2010a), ou seja, "se eu sou, penso e falo X por essas razões enquanto o outro é, pensa e fala Y por outras razões"; 
- Transformação: atividades que desenvolvem a 'transposição' da expansão ocorrida a novas situações em diferentes contextos, de forma a contribuir para a formação de cidadãos éticos e responsáveis (porque conhecem a heterogeneidade para além da sala de aula, em outras práticas sociais) (DUBOC, 2015, p. 222-223, ipsis litteris).

Para finalizar essa seção, caberiam algumas linhas acerca da relevância desta proposta de produção de Recursos Educacionais Abertos (REA) na perspectiva dos Letramentos Críticos. A esse respeito, valeria a pena tecer, pelo menos, duas considerações: a) $\mathrm{O}$ interesse pelo embasamento teórico de materiais de ensino digitais que há décadas vem despertando o interesse de diversos pesquisadores do ensino de línguas (e.g. LEFFA, 2006; VETROMILLE-CASTRO et al., 2012; BEVILÁQUA, 2017); b) Diversas pesquisas indicam que livros didáticos, aplicativos de celular e outros artefatos para o ensino de línguas frequentemente reforçam estereótipos culturais, de gênero, com relação às pessoas ditas do terceiro mundo, entre outros (DUBOC, 2015; VAN DIJK, 2017; VETROMILLE-CASTRO, 2017). Quando produzidos na perspectiva dos Letramentos Críticos, acreditamos que os REA podem suprir lacunas dessa natureza, não apenas dando consistência teórica às atividades para o ensino de línguas, mas também colocando linguagens e tecnologias a serviço de uma ética mais responsiva a questões de gênero, raça, classe, entre outras. Além disso, algumas características fundamentais desses recursos nos resultam particularmente interessantes para o ensino de línguas, tais como a produção de materiais a partir de anseios e necessidades dos estudantes, a possibilidade de adaptação desses materiais em diferentes níveis (HILTON et al., 2010), o licenciamento com uma licença Creative Commons que esclarece liberdades e restrições para o material, entre outras. Para mais informações sobre os REA, sugerimos publicações precedentes sobre o assunto, tais como Costa et al. (2016), Beviláqua et al. (2017) e Beviláqua (2017).

\section{CONTEXTO DA PESQUISA}

O presente estudo, de natureza qualitativa e de cunho fenomenológico (BOGDAN E BIKLEN, 1996), foi realizado na disciplina "Oficina de Produção Textual", da Licenciatura em Letras Espanhol e Literaturas a distância, na Universidade Federal de Santa Maria (UFSM), em parceria com a Universidade Aberta do Brasil (UAB). No contexto dessa disciplina, o primeiro autor deste artigo desempenhou a função de tutor a distância, realizando tarefas como dar feedback, 
esclarecer dúvidas, sugerir melhorias nas atividades da professora formadora ou, até mesmo, propor novas atividades, como é o caso da apresentada neste artigo.

Ao todo, a disciplina foi ministrada em seis polos de apoio presencial, a saber, Constantina, Sobradinho, Tio Hugo, São Francisco de Paula, Itaqui e Quaraí, todos situadas no estado do Rio Grande do Sul, Brasil. As duas amostras analisadas no presente estudo, no entanto, foram retiradas dos dois polos em que atuava o primeiro autor, isto é, Sobradinho e Constantina. Além disso, vale destacar que a análise dos eventos discursivos foi realizada à luz do marco tridimensional proposto por Fairclough (2008), apresentado na revisão de literatura.

Para a produção do REA, recorremos ao Sistema de Autoria Aberto (SAA) Ensino de Línguas Online (ELO) (Disponível em https:/www.elo.pro.br/cloud/), sobre o qual é possível obter mais informações em Beviláqua et al. (2017). Depois de produzido, o material ainda foi integrado ao Ambiente Virtual de Aprendizagem (AVA) Moodle, com o consentimento da professora formadora e dos(as) demais tutores(as) da disciplina.

\section{RESULTADOS E DISCUSSÕES}

O REA "Nuestra Acción es Poética" foi produzido e disponibilizado no Sistema de Autoria Aberto (SAA) (BEVILÁQUA et al. 2017) Ensino de Línguas Online (ELO), no qual pode ser reusado, remixado, revisado e redistribuído (HILTON et al., 2010), tanto por seus proponentes quando por outros(as) educadores(as) que desejem fazê-lo. Esse material é composto por nove módulos, a saber, "hipertexto", "composer", "quiz" (incluindo questões "dialógicas" e de "múltipla escolha"), "sequência", "memória", "eclipse", "cloze", "composer" e "composer", respectivamente. Como é possível observar, o módulo "composer" foi utilizado três vezes ao longo do REA, porém de formas totalmente diferentes.

O REA trata de três aspectos principais, isto é, a prática social "mural literário", o tema transversal "xenofobia" e a forma e função do artigo neutro "lo". Para isso, recorre, principalmente, aos dois textos de apoio descritos a seguir: a) Fotos de diversos murais do movimento mural-literário "Acción Poética"; b) O micro-documentário "Acción Poética - Trujillo, Perú", no qual são explicitados aspectos como finalidade do movimento, fundador, regras, locais e meios de circulação, etc.

É importante destacar, ainda, que o material está dividido em duas etapas principais, sendo a primeira de compreensão e interpretação (oito primeiros 
módulos), e a segunda de produção (último módulo). A organização geral do REA pode ser vislumbrada na Figura 1:

\section{REA}
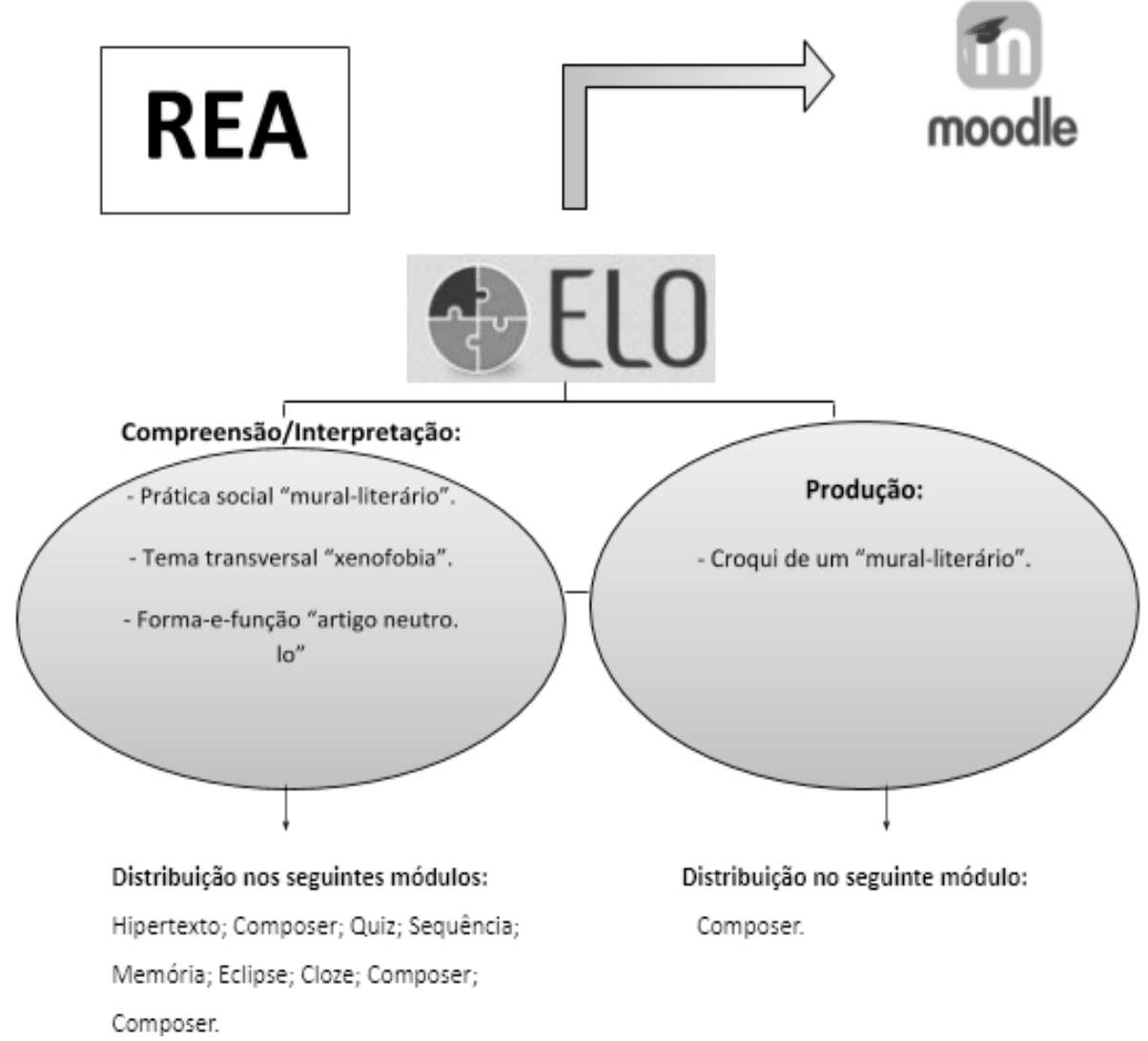

Figura 1. Organização geral do REA "Nuestra Acción es Poética" Fonte: os autores.

Conforme sugere a Figura 1, após a produção e o armazenamento do REA no ELO, o material foi integrado ao Ambiente Virtual de Aprendizagem (AVA) Moodle. Nessa plataforma, estava sendo ministrada a disciplina "Oficina de Produção Textual", a qual é ofertada, em caráter obrigatório, para o terceiro semestre da Licenciatura em Letras a distância da Universidade Federal de Santa Maria (UFSM), em parceria com a Universidade Aberta do Brasil (UAB).

Aspectos contemplados pela atividade, como é o caso da compreensão, da interpretação e da produção de práticas sociais de leitura e escrita, estavam previstos na ementa da disciplina, podendo ser considerados objetivos primários do REA desenvolvido. 
A elaboração do material ambicionou, ainda, problematizar o papel de linguagens e tecnologias diante de problemas sociais como a xenofobia, amplamente presentes no cotidiano de centenas de seres humanos, tanto no âmbito da educação formal quanto em outras esferas da atividade humana. Esse poderia ser entendido como um objetivo secundário do material, já que não estava na ementa da disciplina, mas é inerente ao modus operandi do educador que o propôs, a saber, o primeiro autor deste estudo.

Em outras palavras, tendo em vista que os(as) educadores(as) em formação que fizeram a atividade possivelmente enfrentarão questões de gênero, raça, classe, entre outras, tanto na sala de aula de línguas estrangeiras quanto em outras esferas da vida cotidiana, entendemos como um dever das Licenciaturas em Letras prepará-los(as), na medida do possível, para lidar com tensões dessa natureza, fazendo o uso de linguagens e tecnologias para isso. Nesse sentido, insistimos em uma prática pedagógica que trate dessas questões nos mais diversos níveis e modalidades educacionais: da Educação Básica ao Ensino Superior, da modalidade presencial a modalidade a distância, etc.

Temos encontrado, na perspectiva dos Letramentos Críticos, importantes diretrizes para um trabalho nessa direção. Tendo em vista que materiais de ensino como os REA costumam nortear as produções textuais/discursivas de nossos(as) educandos(as) em sala de aula, esta tem sido, também, a perspectiva que orienta a elaboração de nossas atividades no âmbito pedagógico, cujos princípios teóricometodológicos são apresentados com mais profundidade na segunda seção deste estudo. Interessa-nos, neste momento, demonstrar a aplicação de alguns desses princípios no REA "Nuestra Acción es Poética", conforme vemos na Figura 2:

\section{(4) ELO की Estudante Atividades Nuestra acción es poética}

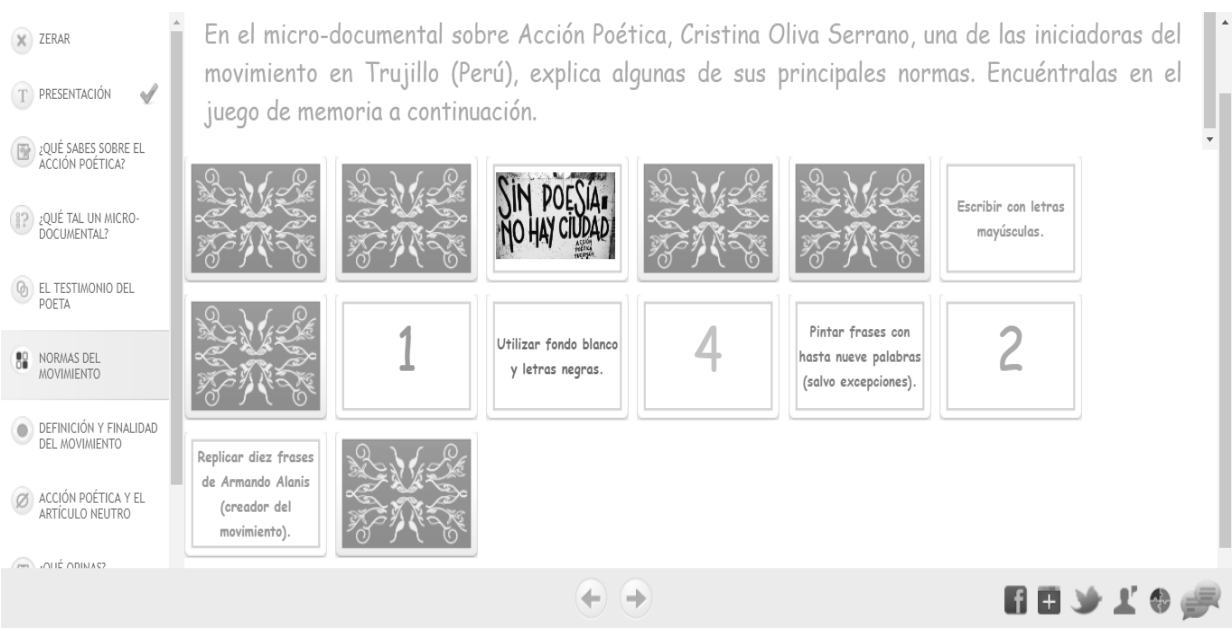

Figura 2. Regras do movimento Acción Poética (módulo "memória")

Fonte: os autores 
Na Figura 2, o módulo "memória" recupera as regras do movimento "Acción Poética", segundo Cristina Oliva Serrano, uma das precursoras do movimento na cidade de Trujillo, Peru. Conforme a muralista explica no decorrer do microdocumentário "Acción Poética - Trujillo, Perú", o qual foi apresentado em módulos anteriores do REA, são regras do movimento mural-literário: replicar dez frases de Armando Alanís Pulido (fundador do movimento), utilizar fundo branco e letras pretas, escrever com letras maiúsculas, pintar frases com até nove palavras, pedir permissão nas paredes, escrever com ortografia correta.

Do nosso ponto de vista, esse módulo vai ao encontro de, pelo menos, dois princípios teórico-metodológicos dos Letramentos Críticos, a saber: a) a noção de linguagem como prática social (FAIRCLOUGH, 2008), uma vez que as características dos murais são deduzidas de um micro-documentário sobre o assunto; b) a etapa que Duboc (2015) chama de "experiências com o novo", visto que as manifestações artísticas de rua nem sempre são compreendidas em suas especificidades, sendo imediatamente rotuladas como mero "vandalismo" (no caso do movimento "Acción Poética", por exemplo, é preciso seguir determinadas regras para pintar os murais, tais como pedir permissão nas paredes).

Após realizar os oito módulos destinados a compreensão e a interpretação dos murais literários, tal como demonstra o exemplo da Figura 2, o(s) educadores(as) em formação foram convidados(as), no módulo final, a produzir o croqui ${ }^{1}$ de um muralliterário, seguindo as características do movimento "Acción Poética", podendo contar com o auxílio de aplicativos de celular (Canva, Phonto ou o próprio stories do Facebook, Instagram, etc.) Alguns tutoriais foram disponibilizados para ajudá-los(as) nesse processo. Além disso, essa produção deveria levar em consideração o tema "xenofobia", uma minuciosa pesquisa sobre a imigração do México para os EUA e a análise do emblemático mural "También de este lado hay sueños", pintado na fronteira entre esses dois países, conforme podemos observar na Figura 3:

1. Entendemos como croqui uma espécie de esboço. Pretendemos, no futuro, em parceria com a coordenação do curso, desenvolver um projeto com a pintura de murais-literários. Até a publicação do estudo, no entanto, isso ainda não foi possível, tanto pela distância geográfica dos polos quanto pelos cortes no orçamento público, cada vez mais acentuado nas Universidades brasileiras. 


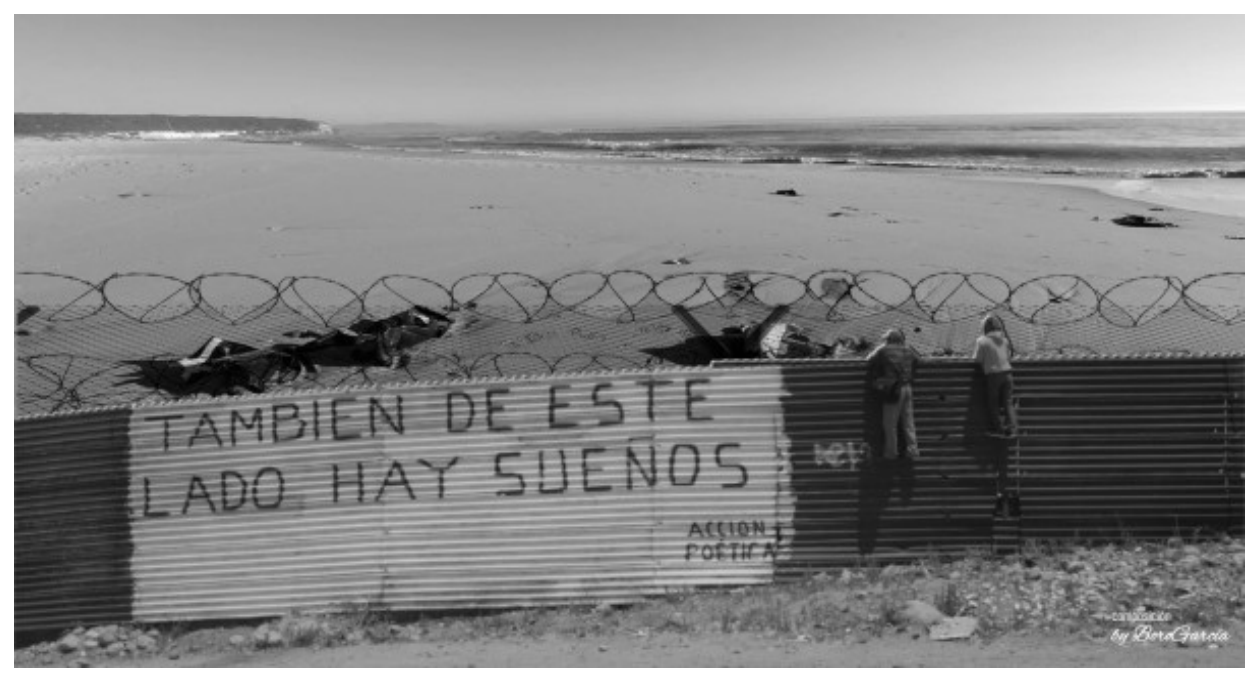

Figura 3. Mural "También de este lado hay sueños".

Fonte: https://alvent.wordpress.com/2016/05/12/al-otro-lado-hay-suenos/. Acesso: 16.02.2019

É importante mencionar que, mesmo durante os módulos de compreensão e interpretação, os(as) educadores(as) não fizeram apenas atividades de memória, preencher lacunas, múltipla escolha, etc., mas também foram solicitados a responder diversas questões na modalidade escrita, por meio das quais tivemos condições de ir sugerindo algumas adequações quanto à língua espanhola. Para fins de análise, no entanto, levamos em consideração apenas duas amostras das produções finais, sendo a primeira do polo de Constantina e a segunda do polo de Sobradinho: 


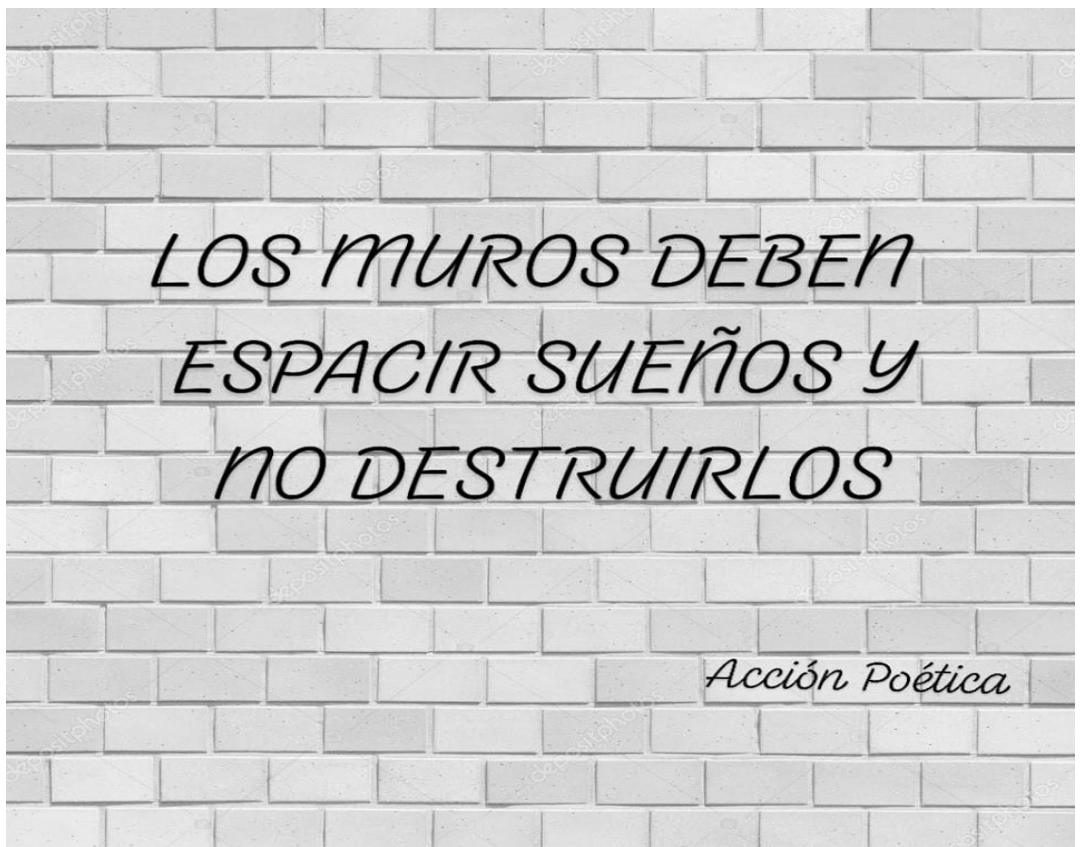

Figura 4. Evento discursivo 1 (Educador(a) em formação A)

Fonte: Ambiente Virtual de Aprendizagem (AVA) Moodle. Disciplina "Oficina de Produção Textual".

Analisando o evento discursivo enquanto texto (Figura 4), levamos em consideração que este parece revelar não apenas um posicionamento favorável ao movimento mural-literário "Acción Poética", mas também uma crítica aos muros que separam as nações umas das outras, como é o caso do que já existia e está sendo ampliado na fronteira do México com os Estados Unidos da América. Em outras palavras, enquanto aquele é responsável por "espalhar sonhos", levando mensagens de motivação, alegria, crítica social, etc. às pessoas que acompanham o movimento, este serve apenas para "destruí-los", impedindo que imigrantes busquem uma vida melhor em outro país. Da nossa perspectiva, tais aspectos têm relação com os significados ideacionais e interpessoais da análise do evento discursivo enquanto texto, uma vez que revelam não apenas como o(a) educador(a) em formação representa o mundo e a própria experiência, mas também como é formado por - e também ajuda a formar - significados sociais com relação a esse tópico específico.

Algumas "pistas" no texto nos permitem esse tipo de interpretação (significados textuais). De um lado, podemos considerar alguns aspectos mais genéricos, a exemplo da própria estética do movimento Acción Poética (fundo 
branco, letras pretas, caixa alta, frases com até nove palavras, assinatura do movimento na lateral inferior direita do mural etc.). Com relação a isso, caberia apenas uma ressalva quanto à grafia inadequada da palavra "esparcir", uma vez que, segundo as regras do movimento, as frases pintadas não devem apresentar desvios ortográficos.

De outro lado, podemos levar em conta a ética desse mesmo movimento, que inclui questões como a difusão da literatura - tanto de autores "consagrados" quanto de "anônimos" -, assim como o combate à cultura da não leitura e a difusão de mensagens de motivação, alegria, crítica social etc. às pessoas que seguem o movimento nas ruas e nas redes sociais. Ética e estética que podem ser deduzidas dos próprios murais, mas que também são reiteradas no micro-documentário "Acción Poética Trujillo, Peru", utilizado como texto de apoio para o estudo desse evento discursivo.

Além disso, existem outras "pistas" quanto à forma-e-significado do texto que corroboram essa interpretação. Ao mesmo tempo em que o pronome "-los", associado ao verbo "destruir" (infinitivo), faz referência ao substantivo "sonhos", o advérbio "não" sugere esta ação ("destruir sonhos") não "deve" (verbo em elipse) ser realizada pelo sujeito ("muros"). Tendo em vista tanto os nossos conhecimentos prévios sobre muros fronteiriços quanto o tema indicado para a produção textual ("xenofobia") e o mural fornecido como texto de apoio para essa produção ("También de este lado hay sueños"), ficaria difícil imaginar outra situação em que um muro pudesse destruir sonhos. Nesse sentido, entendemos que, no tocante à análise do evento discursivo enquanto texto, instaura-se um discurso contrário a qualquer construção dessa natureza na fronteira, consequentemente um discurso contra a xenofobia.

No que diz respeito à análise do evento discursivo como prática discursiva, vale reiterar que este foi produzido no âmbito acadêmico, mais especificamente na disciplina "Oficina de Produção Textual", da Licenciatura em Letras Espanhol (UFSM/UAB). A distribuição deste, portanto, foi na própria ferramenta em que o REA estava armazenado - a saber, o ELO -, chegando a ser compartilhado, também, no caso específico do(a) educador(a) em formação "A", na Rede Social Facebook. Em se tratando de internet e redes sociais, ficaria difícil oferecer informações precisas quanto ao consumo do evento discursivo, mas acreditamos que tenha ficado circunscrito à professora formadora, aos tutores, aos colegas e aos amigos do(a) educadora(a) em formação na rede social Facebook.

Ainda no que tange à análise do evento discursivo como prática discursiva, é interessante considerar as relações entre o evento discursivo e a ordem do discurso, 
bem como a constituição do evento discursivo a partir de diferentes gêneros e discursos. Tais aspectos ficam mais evidentes se consideramos, por exemplo, a própria ética e estética do movimento Acción Poética, conforme mencionamos em linhas anteriores. Em outras palavras, além da parede branca, com letras pretas e em caixa alta, imitar a página de um livro, conforme ratifica uma das muralistas do movimento no documentário "Acción Poética Trujillo, Peru", o movimento foi criado com a finalidade de democratizar o acesso à literatura, estimular a leitura, levar às pessoas mensagens de motivação, reflexão, etc. Nesse sentido, um movimento marginal, sem nenhum tipo de relação aparente com a academia, pode ter muito mais em comum com esse domínio do que podemos imaginar, com a diferença de ser muito mais acessível às camadas que ocupam a base da pirâmide social. Além dessa constatação com relação à ordem do discurso, é possível perceber, no evento discursivo, a tensão entre, pelo menos, dois discursos, um hegemônico, ao qual se opõe terminantemente ("muros devem afastar estrangeiros que vêm roubar nossos empregos, trazer doenças, etc."), e um contra-hegemônico, ao qual ideologicamente parece se filiar ("muros devem servir para espalhar sonhos por meio de expressões artísticas e/ou literárias").

No que tange à analise do evento discursivo como prática social, além de aspectos mencionados anteriormente, sobretudo com relação ao contexto imediato e institucional, podemos levar em consideração o contexto mais amplo ou de cultura. Tendo em vista a forte onda de discriminação contra imigrantes, tanto a nível nacional quanto internacional, fazendo referência aqui a países como os EUA, é importante ressaltar que o evento discursivo em questão se opõe, discursivamente, a esse tipo de postura. Isso só foi possível, evidentemente, porque o REA possibilitou esse tipo de diálogo, solicitando que os(as) educadores(as) em formação se posicionassem, por meio de linguagens e tecnologias, a respeito dessa questão. Nesse sentido, acreditamos que o REA na perspectiva dos Letramentos Críticos propiciou affordances para a produção de eventos discursivos sensíveis a problemas sociais como a xenofobia, cumprindo com um dos objetivos para o qual foi desenvolvido. Diante de tais considerações, podemos passar para a análise do segundo evento discursivo produzido a partir do REA, conforme vemos na Figura 2: 


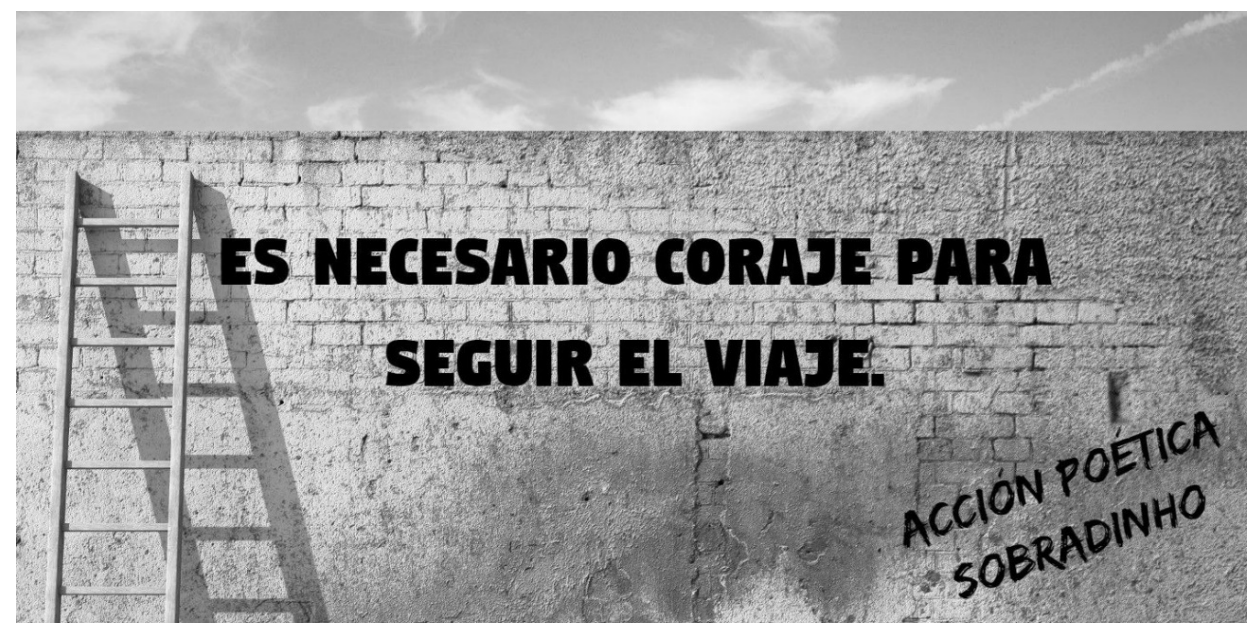

Figura 5. Evento discursivo 2 (educador(a) em formação B)

Fonte: Ambiente Virtual de Aprendizagem (AVA) Moodle. Disciplina "Oficina de Produção Textual".

No que diz respeito ao evento discursivo como texto, consideramos que este apresenta uma mensagem de otimismo a quem ainda não atravessou a fronteira, demonstrando solidariedade a pessoas nessa situação. No nosso entender, essa postura está relacionada aos significados ideacionais e interpessoais do evento discursivo enquanto texto, uma vez que revela o modo como o(a) educador(a) em formação representa o mundo e a própria experiência, ao mesmo tempo em que forma e é formado por significados sociais sobre o tópico em questão.

Existem "pistas" no texto que nos possibilitam esse tipo de interpretação. Além de aspectos mais genéricos quanto à organização do texto, tais como a ética e a estética do movimento "Acción Poética", sobre as quais já tratamos com maior riqueza de detalhes em momentos anteriores deste trabalho, podemos destacar a relação entre o heterogenérico "viagem" e outros recursos semióticos, como a escada apoiada no muro. Dito de outra forma, é difícil imaginar outro tipo de viagem em que seja necessário atravessar um muro com a ajuda de uma escada, senão no contexto de imigração. Além disso, o mural sugere que será necessário ter "coragem" durante esse trajeto, visto que os perigos e riscos de uma viagem nessas condições costumam ser muito maiores do que os de uma viagem pelas vias convencionais.

Ainda quanto aos significados textuais, é interessante notar que, apesar de a atividade não exigir que os(as) educandos(as) empreguem, nas produções finais, o artigo neutro "lo", eventos discursivos como o da Figura 5 parecem indicar algum 
nível de compreensão quanto ao uso adequado de tal forma-e-função. Em outras palavras, ainda que, por um lado, o evento discursivo não considere o uso do artigo neutro "lo", por outro lado, demonstra o entendimento de que essa forma-e-função nunca deve anteceder substantivos como "viaje", recorrendo apropriadamente ao artigo masculino singular "el".

Quanto à análise do texto como prática discursiva, caberia acrescentar, aos aspectos mencionados na análise do evento discursivo 1, que desta vez o mural literário também instaura um discurso solidário aos imigrantes ilegais, mas mais brando com relação ao modo adotado por países como os EUA para conter a imigração. Dito de outra forma, o mural 1 parece ir além no sentido de instaurar um discurso terminantemente contrário a construções dessa natureza na fronteira, ao passo que o 2 apenas se revela solidário com os imigrantes que buscam atravessá-las.

Com relação à análise do evento discursivo como prática social, optamos, novamente, por evitar redundâncias quanto ao contexto imediato, institucional ou de cultura deste, uma vez que é possível encontrar mais informações sobre tais aspectos em etapas anteriores do estudo. Caberia ressaltar, contudo, que entendemos que, nesse segundo caso, o REA também cumpriu com o objetivo para o qual foi desenhado, propiciando affordances para a produção de um evento discursivo sensível à questão da xenofobia.

\section{CONSIDERAÇÕES FINAIS}

Retomando o incidente com o sírio Mohamed Ali, narrado na introdução deste artigo, vale destacar que centenas de brasileiros(as) demonstraram-se solidários a causa do refugiado, apoiando-o tanto nas redes sociais quanto presencialmente. Um grupo de pessoas chegou, inclusive, a organizar um "esfirraço" a favor de Mohamed, aumentando consideravelmente suas vendas no período em que o ataque xenofóbico aconteceu.

Isso só foi possível porque, apesar das forças conservadoras que crescem com força e velocidade alarmantes no Brasil, ainda vivemos em uma democracia, na qual ainda gozamos de alguma liberdade de pensamento, tanto dentro quanto fora das instâncias formais de ensino. Além disso, é provável que as pessoas que intercederam por Mohamed tenham tido, em algum momento de sua formação, seja na educação formal, seja fora dela, possibilidades de exercitar a empatia com setores marginalizados da nossa sociedade, tornando-se mais sensíveis com relação a temas como a xenofobia. 
No que compete ao presente estudo, esperamos ter contribuído para que tensões dessa natureza não passem despercebidas no âmbito da educação linguística do ensino de línguas estrangeiras, inclusive nos materiais de ensino que facilitam a compreensão e a produção de práticas sociais de leitura e escrita nesse contexto.

Nesse sentido, o presente trabalho tinha como objetivo geral investigar em que medida um Recurso Educacional Aberto (REA) na perspectiva dos Letramentos Críticos pode propiciar (ou não) affordances para a produção de eventos discursivos sensíveis a problemas sociais como a xenofobia. Para isso, perseguimos três objetivos específicos, a saber: a) Apresentar o REA desenvolvido (objetivos do material, princípios teórico-metodológicos que nortearam o seu desenvolvimento, materiais e ferramentas utilizados durante a sua produção, etc.); b) Analisar duas amostras dos eventos discursivos oriundos desse REA, com vistas a identificar indícios de Letramentos Críticos; c) Discutir possibilidades teórico-metodológicas para o redesign desse material.

Com o cumprimento desses três objetivos específicos, concluímos, no presente artigo, que REA na perspectiva dos Letramentos Críticos podem propiciar affordances para a produção de eventos discursivos sensíveis a problemas sociais como a xenofobia, uma vez que, apesar da pequena quantidade de amostras analisadas, foi possível identificar indícios de um Letramento Crítico no que diz respeito a tal questão. Esperamos, futuramente, ampliar o número de amostras, apontando também casos que tiveram menor sucesso, bem como motivações possíveis para isso.

\section{REFERÊNCIAS}

ATAQUE a refugiado sírio coloca em xeque a fama do brasileiro acolbedor (2017). São Paulo: Recordtv. (15 min.), son., color. Disponível em: <https://www.youtube.com/ watch?v=f2tXhGWh1aU > . Acesso em: 10 mar. 2019.

BEVILÁQUA, A. F. (2017). Linguagens e tecnologias a serviço de uma Ética Maior: a produção de Recursos Educacionais Abertos na perspectiva dos Letramentos Críticos. 2017. 114 f. Dissertação (Mestrado em Linguística Aplicada) - Programa de Pós-Graduação em Letras, Universidade Católica de Pelotas (UCPEL), Pelotas, RS.

BEVILÁQUA, A. F. et al. (2017) Ensino de Línguas Online: um Sistema de Autoria Aberto para a produção e adaptação de Recursos Educacionais Abertos. Calidoscópio, São Leopoldo, v. 15, n. 1, p. 190-200. Universidade do Vale do Rio dos Sinos (UNISINOS). 
BOGDAN, R. C.; BIKLEN, S. K. (1994). Investigação qualitativa em educação. Uma introdução à teoria e aos métodos. Porto, Portugal: Porto Editora.

CASSANY, D.; CASSTELLÀ, J. (2010). Aproximación a la Literacidad Crítica. Perspectiva, Florianópolis, v. 28, n. 2, p. 353-374. Universidade Federal de Santa Catarina (UFSC).

COSTA, A. R. et al. (2016) Contribuindo com o estado da arte sobre Recursos Educacionais Abertos para o ensino e a aprendizagem de línguas no Brasil. Veredas On-line, Juiz de Fora, v. 20, n. 1, p. 1-20.

DUBOC, A. P. (2015). Letramento Crítico nas brechas da sala de aula de línguas estrangeiras. In: TAKAKI, N. H.; MACIEL, R. F. Letramentos em terra de Paulo Freire. 2. ed. Campinas: Pontes, p. 209-229.

LEFFA, V. J. (2006). Nem tudo o que balança cai: Objetos de Aprendizagem no ensino de línguas. Polifonia, Cuiabá, v. 12, n. 2, p.15-45.

MENDONÇA, H. (2018). O "monstro da xenofobia" ronda a porta de entrada de venezuelanos no Brasil. El País, Roraima, 27 ago. 2018. Disponível em: < https:// brasil.elpais.com/brasil/2018/08/17/politica/1534459908 846691.html>. Acesso em: 10 mar. 2019.

FAIRCLOUGH, N. (1993). El análisis crítico del discurso y la mercantilización del discurso público: las universidades. Trad. Elsa Ghio. Discurso \& Sociedad, [online], v. 2, n. 1, p. $170-186,2008$.

FREIRE, P. (2016). Pedagogia da autonomia: saberes necessários à prática educativa. 54. ed. Rio de Janeiro: Paz e Terra.

TALENTO, A. (2013). Ministério da saúde chama de "xenofobia" protesto contra médicos no CE. Folha de São Paulo, Fortaleza, 27 ago. 2013. Disponível em: < http://folha.com/

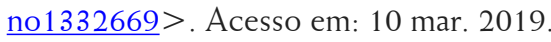

HILTON, J. et. al. (2010). The four R's of openness and ALMS analysis: frameworks for Open Educational Resources. Open Learning: the journal of open and distance learning, v. 25, n. 1, p. 37-44.

HORKHEIMER, M. (1968). Teoría Crítica. Trad. Edgardo Albizu e Carlos Luis. Buenos Aires: Amorrortu, 2003. 
MOITA LOPES, L. P. da. (2006). Linguística Aplicada e vida contemporânea: problematização dos construtos que têm orientado a pesquisa. In: MOITA LOPES, L. P. da. Por uma Linguística Aplicada Indisciplinar. São Paulo: Parábola, p. 85-107.

PENYCOOK, A. (2006) Uma Linguística Aplicada transgressiva. In: LOPES, L. P. da M. Por uma Linguística Aplicada Indisciplinar. São Paulo: Parábola, p. 67-84.

SOARES, M. B. (2004). Letramento e alfabetização: as muitas facetas. Revista brasileira de educação, [online], v. 1, n. 25, p.5-17.

VAN DIJK, T. (2008). A. Discurso e Poder. Trad. e adaptação Judith Hoffnagel, Ana Regina Vieira, Leonardo Mozdzenski, Benedito Gomes Bezerra, Rodrigo Castro e Karina Falcone. 2. ed. São Paulo: Contexto, 2017.

VETROMILlE-CASTRO, R. et al. (2012). Objetos de Aprendizagem de Línguas: uma proposta. In: VETROMILLE-CASTRO, R.; HEEMANN, C.; FIALHO, V. R. Aprendizagem de línguas - a presença na ausência: CALL, Atividade e Complexidade. Pelotas: Educat, p. 242-256.

VETROMILLE-CASTRO, R. (2017). Língua como instrumento, língua para o poder: Reflexões sobre o papel do professor, tecnologias digitais e desenvolvimento linguístico. In: TAKAKI, N. H.; MOR, W. M. Construções de sentido e letramento digital crítico na área de línguas/linguagens. Campinas: Pontes, p. 195-219.

Recebido: 7/04/2019

Aceito: 7/07/2019

Publicado: 1/08/2019 